\title{
FORMAÇÃO INCIAL DO COORDENADOR PEDAGÓGICO: aná- lises e reflexões dos saberes profissionais
}

\author{
INITIAL TRAINING OF AN EDUCATIONAL COORDINATOR: reflections on profes- \\ sional knowledge
} FORMACIÓN INICIAL DEL COORDINADOR PEDAGÓGICO: análisis y reflexiones
del conocimiento profesional

\author{
Susana Soares Tozetto \\ Professora Doutora do departamento de educação e do \\ Programa de pós-graduação da Universidade Estadual de Ponta Grossa - UEPG. \\ tozettosusana@hotmail.com \\ Priscila Kailer \\ Professora da Rede Pública de Ponta Grossa (SME). \\ tozettosusana@hotmail.com
} Mestre pelo Programa de Pós-Graduação em Educação da Universidade Estadual de Ponta Grossa - UEPG.

\begin{abstract}
RESUMO: O presente artigo analisa os saberes da formação inicial do coordenador pedagógico. O cotidiano desse profissional, imerso por acontecimentos imprevisíveis, mobiliza saberes a cada nova situação Os autores que sustentam as análises aqui propostas são Kuenzer(2006), Gauthier (1998) e Gimeno Sacristán (1999). Assim, foi feito uma análise documental do Projeto Político Pedagógico do curso de Pedagogia da Universidade Estadual de Ponta Grossa-Pr entre os anos de 2007 a 2010. Os dados da pesquisa também foram obtidos com entrevistas de seis coordenadoras pedagógicas egressas do curso em análise. Os resultados mostram que a amplitude do processo formativo do coordenador pedagógico desafia as possibilidades de formar um profissional para diversas funções, como docente, gestor e pesquisador.
\end{abstract}

PALAVRAS-CHAVE: Formação Inicial. Saberes. Coordenador Pedagógico.

ABSTRACT: This article analyzes knowledge in initial educational coordinator training. The daily life of this professional, immersed in unforeseeable events, mobilizes knowledge for each new situation Authors argue that the analyses proposed here are Kuenzer (2006 ), Gauthier (1998) and Gimeno Sacristan (1999). Thus, document analysis was carried out on the Political Pedagogical Project of the Faculty of Education at the State University of Ponta Grossa -PR from 2007 to 2010. Research data was also obtainedthrough the interviews of six educational coordinators of the major under anlysis.. Results show that the amplitude of educational coordinator training training process challenges the possibilities of preparing a professional for various functions such as a teacher, manager and researcher.

KEYWORDS: Initial Training. Knowledge. Educational Coordinator.

RESUMEN: En este artículo se analiza el conocimiento de la formación inicial del coordinador pedagógico. La vida cotidiana de este profesional, inmersa por acontecimientos imprevisibles, moviliza el conocimiento a cada nueva situación. Los autores que sostienen los análisis que aquí se proponen son Kuenzer (2006), Gauthier (1998) y Gimeno Sacristán (1999). Por lo tanto, se realizó un análisis documental del Proyecto Político Pedagógico del Curso de Pedagogía de la Universidad Estadual de Ponta Grossa - PR entre los años 2007 a 2010. Los datos de la investigación se obtuvieron también con encuestas a seis coordinadoras pedagógicas egresas del curso en análisis. Los resultados muestran que la amplitud del proceso de formación del coordinador pedagógico desafía las posibilidades de formar un profesional para diversas funciones, como maestro, director e investigador.

PALABRAS CLAVE: Formación inicial. Conocimiento. Coordinador pedagógico.

Artigo recebido em setembro de 2016

Aprovado em novembro de 2016 


\section{1| INTRODUÇÃO}

O entendimento da educação como um vetor fundante da modernidade colocou o profissional do ensino em um espaço central e, consequentemente, a sua formação para exercer a profissão conforme os ideários modernos. Apesar de a formação de professores não ser uma preocupação recente, a temática obteve centralidade nas últimas décadas em virtude das exigências sobre ela. Novas responsabilidades foram atribuídas ao docente decorrente do projeto neoliberal de sociedade e das demandas que a universalização do ensino proporcionou.

Frente ao contexto, ressaltamos a importância de uma formação que ofereça uma bagagem sólida de saberes específicos do trabalho do coordenador pedagógico, que, para tanto, volte seu olhar aos processos educacionais, sem distanciar do âmbito escolar e dos saberes que norteiam a prática pedagógica. Assim, pontuamos que o curso de Pedagogia se constitui em espaço privilegiado para essa formação, o qual possibilita condições de problematizar a prática pedagógica e de constatar/discutir a lógica ideológica, política e pedagógica que marca o trabalho na sociedade capitalista (PABIS, 2014).

O papel do coordenador pedagógico não é neutro, considerando que há sempre um posicionamento presente na prática pedagógica que pode realizar tanto a transformação como a confirmação do status quo. Apesar do consenso legal sobre a importância dos saberes pedagógicos para a atuação do coordenador, segundo Pabis (2014), esse profissional permanece como guardião das políticas educacionais, ou seja, como um profissional que se demonstra mais preocupado em implementar as políticas educacionais na escola do que necessariamente voltar-se ao processo de ensino e de aprendizagem.

Ao tratar do rigor científico do trabalho do coordenador pedagógico, os saberes específicos devem ser apropriados no âmbito da formação especializada do coordenado. É a formação inicial que possibilita bases para o coordenador realizar seu trabalho de forma autônoma e consciente sobre sua prática, sem cair nas ações imediatas e fragmentadas, e, consequentemente, na perda da dimensão totalitária de sua função. Nessa perspectiva, defendemos a necessidade de o coordenador pedagógico ser formado em um curso de Pedagogia com consistência teórica, que possibilite a compreensão dos determinantes sociais, políticos e econômicos da educação.

Para o presente estudo, apresentamos as discussões que envolvem os saberes específicos do coordenador pedagógico com base em Gauthier (1998) e Tardif (2002). Posteriormente, enfocamos a formação inicial do coordenador pedagógico da Universidade Estadual de Ponta Grossa - PR (2007-2010), com a análise da reformulação e da elaboração do Projeto Político Pedagógico (PPP) da Licenciatura em Pedagogia. Discorremos também sobre as etapas da investigação, nas quais apontamos o campo, os sujeitos, os instrumentos e a análise dos dados. E por fim apresentamos os resultados da pesquisa que envolve os saberes do coordenador pedagógico.

\section{2 | OS SABERES DO COORDENADOR PEDAGÓGICO}

Ao tratar dos saberes, Tardif (2002) denota que o conjunto de processos formativos e de aprendizagem socialmente elaborados destina-se a instruir os professores. Para isso, cabe aos educadores que passam pelos processos educativos na formação, definir suas práticas em relação aos saberes que possuem e transmitem (TARDIF, 2002). Entretanto, o escopo dos saberes deixa de ser entendido como elemento exclusivo dos docentes e envolve os grupos de educadores, incluindo o coordenador como o profissional responsável na organização do trabalho pedagógico na escola. 
Ao apresentar os saberes do coordenador pedagógico, André e Vieira (2007) ressaltam o cotidiano desse profissional, que, imerso por acontecimentos imprevisíveis, mobiliza saberes a cada nova situação. Com base nas autoras, evidenciamos que, no trabalho do coordenador pedagógico, se faz necessário saberes para realizar ações que envolvem o planejamento da rotina escolar, o acompanhamento do profissional docente, o atendimento de alunos e de pais. Pontuamos também a importância dos saberes que são mobilizados pelo coordenador pedagógico, nas atribuições que envolvem a formação continuada do professor e a elaboração coletiva do PPP da escola.

Os saberes que envolvem o trabalho do coordenador pedagógico não se manifestam de forma individual. Segundo André e Vieira (2007), no cotidiano da escola, os saberes também são mobilizados nas relações que se estabelecem com professores, alunos e pais. Nesse sentido, são saberes que são produzidos nas suas relações com o outro, das mediações, das orientações, das resoluções dos conflitos, entre outras ações que visem a aprendizagem dos alunos.

A gestão de pessoas, com viés democrático, só pode ser uma realidade quando as ações ultrapassam o âmbito do discurso e se efetivam na escola sustentadas nos princípios dialógicos e na alteridade. O modo como a coordenadora pedagógica mobiliza os saberes no cotidiano da escola denota os sentidos e os significados que as ações são realizadas no espaço da escola. Ou seja, ao privilegiar determinada atuação, o coordenador pedagógico estabelece os saberes que serão mobilizados. Assim, consideramos que, ao realizar uma atuação desordenada, o coordenador pedagógico secundariza saberes pedagógicos do trabalho.

Ao estabelecer as contribuições de alguns autores (TARDIF, 2002; GAUTHIER, 1998), demarcamos a necessidade de analisar os saberes da formação inicial que balizam o trabalho do coordenador pedagógico. A formação do coordenador pedagógico está atrelada à formação do professor, e, desse modo, entendemos que a formação do pedagogo precisa considerar a dimensão teórico-prática da educação. De acordo com Cruz (2009), os saberes pautados nos fundamentos teóricos do pedagogo prevaleceram como principal motriz no início do curso de Pedagogia, que, ao longo dos anos, se modificou a fim de adequar-se às influências da epistemologia da prática.

Os saberes apoiados em uma ciência pura permitia ao coordenador pedagógico exercer sua profissão com semelhança ao técnico. Portanto, o conhecimento específico desse profissional estava restrito ao domínio de conteúdo, que resolvia os problemas encontrados na escola com a aplicação de um repertório de conhecimentos e soluções preestabelecidas cientificamente. A ênfase teórica no curso de Pedagogia, por muito tempo, foi alvo de críticas que, ao não reconhecer a importância da prática no processo de formação, dificultou a formulação de um saber de cunho pedagógico.

Ao conhecer a pluralidade de saberes que envolvem a prática do pedagogo, Cruz (2009), aponta a dificuldade em nomear um saber específico para a Pedagogia, considerando os inúmeros conhecimentos que envolvem a formação e a prática pedagógica desse profissional. Nesse sentido, a autora (CRUZ, 2009, p.13) coloca que o saber da pedagogia deve estar pautado por um entendimento de um saber composto, no qual considera tanto os saberes de base teóricos como também os saberes práticos:

[...] o aprofundamento teórico, pela via das diferentes disciplinas, precisa considerar a educação como prática social e o trabalho pedagógico e docente como a referência primeira da pedagogia e, consequentemente, do seu curso. O tratamento específico dos conhecimentos educacionais, a partir da lógica de cada disciplina e de seu professor, precisa se ligar ao estudo, à reflexão e à pesquisa sobre a educação como prática social, propiciando aos pedagogos em formação fundamentos para teorizar sobre suas práticas e condições para submetê-las à discussão. 
A prática pedagógica não é uma ação mecânica, o coordenador pedagógico e o professor exercem influências que não permitem neutralidades políticas e epistemológicas em suas ações. Para Gimeno Sacristán (1999), a prática é entendida como uma atividade para fins conscientes; assim, o autor aponta que a prática ocorre mediante uma finalidade e visa a transformação de uma realidade - como atividade social, historicamente direcionada para mudança. Dessa forma, a prática pedagógica é entendida como uma práxis que é dotada de sentido.

\section{3 | FORMAÇÃO INICIAL DO COORDENADOR PEDAGÓGICO}

A tendência assumida nas Diretrizes Curriculares Nacionais do Curso de Pedagogia (BRASIL, 2006), após a militância realizada pelo movimento dos professores a favor de integrar a formação docente dos anos iniciais do Ensino Fundamental e da Educação Infantil no âmbito universitário, estabeleceu no Art. 10 a extinção das habilitações dos cursos de Pedagogia, assumindo o entendimento da formação do pedagogo com base na docência e não mais na formação do especialista.

Apesar dos avanços no curso de formação do Pedagogo, ressaltamos a necessidade de repensar sobre o significado da atuação docente e pedagógica do profissional na escola. Ao elaborar o curso de Pedagogia em uma formação de quatro anos que atende para além da atuação docente, como também no âmbito da gestão e na formação para a pesquisa, corre-se o risco de um formato aligeirado e abrangente para a formação do pedagogo. Ao considerar essa formação abrangente, destacamos, ainda, sobre o acréscimo de diferentes temáticas, indicadas pelas Diretrizes Curriculares Nacionais, entre elas as disciplinas de Educação no campo, Pedagogia Inclusiva, Educação em espaços não-formais, entre outras.

A configuração do curso proposta nas DCN's (BRASIL, 2006) do curso modificou os antigos moldes de formação e trouxe alterações para as instituições, como a elaboração de novos Projetos Políticos Pedagógicos. Nesse contexto, o curso de Pedagogia da Universidade Estadual de Ponta Grossa elaborou o PPP do Curso com vigência nos anos de 2007, permanecendo até 2010, com as modificações propostas pelas DCN's do curso. Ao considerar a investigação proposta neste trabalho de compreender as contribuições da formação inicial da licenciatura em Pedagogia da UEPG (2007-2010), fez-se necessária a análise da reformulação e da elaboração do referido PPP.

Com o forte movimento contemporâneo, com ênfase nos aspectos reflexivos, o PPP em análise assume a prática pedagógica como objeto de estudo e de investigação, tendo em vista aproximar a formação dos professores da realidade escolar. A dicotomia entre o local de formação dos professores e o espaço escolar é levantada por Cruz (2009), que o distanciamento provém da ramificação da dimensão teórica e prática do ensino. Nesse sentido, a autora elucida a importância da formação inicial do professor, pois ela se configura como o primeiro passo para o desenvolvimento profissional contínuo. Para isso, é preciso fornecer relações reais de diálogo com a prática - uma prática comprometida, que se coloca além do aspecto da transmissão.

A formação para a docência está pautada por conhecimentos que estão além do espaço de sala de aula. Assim, amplia-se o olhar do docente, que, conforme as DCNP, as atividades docentes compreendem a participação na organização e na gestão de sistemas e de instituições de ensino, configurando uma hierarquia que coloca a docência como hegemônica, ou seja, como base do processo formativo, seguindo-se o conceito de gestão e finalmente o de pesquisa. Desse modo, a concepção de docência proposta como base da formação supõe um conceito alargado, que vai além da relação ensino-aprendizagem e compreende a gestão e a pesquisa.

O egresso do curso de Pedagogia configura-se, portanto, um licenciado apto para atuar na docência como também na equipe gestora, coordenador pedagógico e diretor, do sistema escolar. 
Para Kuenzer (2006), a amplitude do curso resultou em uma formação descaracterizada do pedagogo. No que envolve o PPP do curso Pedagogia em análise (UEPG, 2006), os princípios pedagógicos para a formação do docente e do gestor encontram-se associados. Assim, o documento pontua a docência como ato educativo intencional, entendido em seu sentido amplo, como trabalho e processo pedagógico.

Ressaltamos as disciplinas articuladoras do curso, tendo em vista a importância que elas representam ao possibilitar tempo e espaço para realizar processos de observação, problematização e análise, na compreensão do trabalho pedagógico em um dado contexto histórico, social, cultural e organizacional. As disciplinas articuladoras do curso, conforme o PPP (UEPG, 2006), compreendem disciplinas que se realizam durante todos os anos de formação do pedagogo.

Na formação do gestor e do coordenador pedagógico, denotamos a importância das discussões que permitem um entendimento sobre o escopo mais amplo do trabalho realizado em sala de aula. Não se trata de minimizar as questões que envolvem a sala de aula, mas de compreender que há especificidades no trabalho do coordenador pedagógico que precisam estar fundamentadas pela formação inicial desse profissional. O coordenador pedagógico realiza seu trabalho tanto no suporte ao trabalho do professor - procurando compreender as questões relativas à aprendizagem dos alunos de forma mais direta -, como também na organização do trabalho pedagógico da escola, que necessita de uma clareza de aspectos estruturais e organizacionais. Domingues (2014) afirma que a formação do coordenador pedagógico precisa estar alicerçada em termos conceituais e práticos para subsidiar o trabalho com os professores, com os alunos e com a comunidade.

O eixo articulador do curso compõe, no segundo ano, a disciplina de Pesquisa e Prática Pedagógica I. O PPP (UEPG, 2006) fundamenta o trabalho do futuro gestor com espaços de articulação entre os conhecimentos das disciplinas componentes do curso, dos processos de ensinar e aprender na escola e das práticas de gestão na perspectiva da pesquisa. Observamos uma preocupação de articular a docência, a gestão e a pesquisa, a fim de superar a fragmentação do curso nos três eixos de formação. Para Pabis (2014, p. 89), "[...] o curso continua fragmentado, antes fragmentação entre a formação do professor e o especialista através das habilitações, atualmente a fragmentação entre o professor, o gestor e o pesquisador". Assim, a fragmentação é intensificada pela concepção ampla de docência, que passa a estar integrada à gestão, que, no entanto, não oferece subsídios para compreender as especificidades da atuação da equipe gestora.

A disciplina articuladora do terceiro ano do curso denomina-se Pesquisa e Prática Pedagógica II, que, de acordo com o PPP do curso (UEPG, 2006), tem como um dos objetivos proporcionar a problematização do estágio, com as referências teórico-pedagógicas já incorporadas nas disciplinas anteriores, para refinar o projeto de pesquisa. Nesse enfoque, busca-se, também, uma relação entre os saberes da experiência, os saberes pedagógicos e os saberes específicos das áreas (UEPG, 2006). Com isso, o estágio deixa de ser restrito a um espaço meramente técnico e prático e passa a obter um caráter de formação coletiva, que se desenvolve em consonância com a escola, a universidade e os saberes do estagiário. O estágio deixa, assim, de ser entendido como um acessório do curso e passa a ser valorizado como um elemento chave para a construção da identidade profissional.

Ainda, no terceiro ano do curso, a disciplina articuladora de Seminários Avançados em Gestão I (UEPG, 2006) visa favorecer a aproximação do acadêmico com o trabalho do pedagogo na escola, em sua dimensão de gestão. Para tanto, busca articular os conhecimentos das disciplinas da formação com o trabalho do pedagogo na gestão da escola (UEPG, 2006). Assim, a realidade da organização escolar e das relações pedagógicas é enfocada a partir dos eixos de trabalho do pedagogo na escola: político-administrativo, pedagógico e humano (UEPG, 2006). De acordo com com Pabis (2014), a formação da consciência faz-se a partir da realidade social. No entanto, não se 
trata de qualquer realidade. É preciso uma realidade comprometida, problematizada e pensada; assim, o espaço dessa disciplina na formação possibilita a compreensão do trabalho do pedagogo, na qualidade de coordenador pedagógico e diretor do espaço escolar.

Seminários Avançados das Disciplinas Pedagógicas do Ensino Médio e da Gestão Educacional contemplam o quarto ano do curso a fim de realizar o processo sistemático de indagação e reflexão sobre as questões relacionadas ao ensino, seus condicionantes sociais, políticos, econômicos e culturais, bem como à gestão educacional e à organização do trabalho pedagógico na escola (UEPG, 2006). Conforme o PPP do curso (UEPG, 2006), essa disciplina denota um espaço para reflexão e problematização a partir de momentos de sistematização e síntese da relação teórico-prática.

Entendemos a necessidade de a licenciatura em Pedagogia fornecer espaço de discussão que vise compreender os condicionantes que envolvem o trabalho do coordenador pedagógico, tendo em vista que, no cotidiano da escola, esse profissional é marcado por determinantes sociais, políticos, econômicos, culturais que interferem na sua atuação. Pabis (2014) também aponta a necessidade de os profissionais do ensino, inclusive o coordenador pedagógico, conhecer os determinantes que envolvem a escola e como eles se articulam, a fim de obter condições para planejar, pensar e realizar seu trabalho de forma consciente.

O PPP (UEPG, 2006) também pontua que não há como conceber a formação inicial desse profissional sem o exercício de reflexão e de indagação sobre a realidade. Para tanto, os referenciais que embasam as disciplinas articuladoras do curso (UEPG, 2006) estão em consonância com a perspectiva da prática reflexiva, a saber: Perrenoud (2002), Pimenta (1995), Schön, (2000), entre outros da mesma perspectiva teórica. Esses autores defendem seus pressupostos, em contraponto ao modelo da racionalidade técnica, que hierarquiza e distancia a teoria da prática. Cabe considerar no PPP (UEPG, 2006) que as disciplinas articuladoras do curso não restringem a reflexão ao estágio; ao contrário, inserem a integração e a articulação de todas as disciplinas do curso, a problematização do estágio, como também as discussões que se inserem nesse espaço de articulação.

Destacamos no PPP (UEPG, 2006) as disciplinas de Gestão Educacional I, Gestão Educacional II e Estágio Supervisionado em Gestão Educacional, a fim de compreender a formação do gestor e do coordenador pedagógico no referido curso. Cabe considerar que diferentemente das disciplinas pontuadas anteriormente, elas não se tratam de disciplinas articuladoras, mas se constituem no eixo curricular de Gestão Educacional.

A disciplina Gestão Educacional I aborda a compreensão da escola "[...] como construção histórica, seus sujeitos e organização, suas relações de determinação pela política educacional e o entorno social" (UEPG, 2006, p. 30). A disciplina de Gestão Educacional II contempla as discussões do segundo ano do curso e ressalta a avaliação institucional, o PPP e a formação continuada como processos pedagógicos centrais (UEPG, 2006). O referencial de Canário (2006), Ferreira (2003) e Nóvoa (2002) possibilita discussões que envolvem especificamente o coordenador pedagógico e as atribuições desse profissional.

É importante discutir no curso com as futuras pedagogas que o coordenador pedagógico é articulador do processo de ensino-aprendizagem na escola. Assim, esse profissional atua ao mesmo tempo dentro e fora da sala de aula, ao realizar o suporte ao professor ou na organização do trabalho pedagógico. No entanto, a atuação do coordenador pedagógico precisa estar em consonância com o modelo profissional apreendido no espaço da formação, tendo em vista que é nesse espaço que acontece o desenvolvimento de sua profissão; caso contrário, corre-se o risco de realizar um trabalho pautado por questões imediatas que envolvem a escola. Nesse sentido, entende-se que o coordenador pedagógico precisa ter clareza da importância do seu trabalho e reconhecer as suas atribuições, com destaque para as ações que esse profissional desenvolve na formação continuada, na avaliação institucional, na elaboração coletiva do PPP. 
O Estagio Curricular Supervisionado em Gestão Educacional contempla o quarto ano de formação do pedagogo (UEPG, 2006), com as concepções educacionais vigentes na Educação Infantil e nos anos Iniciais do Ensino Fundamental e Ensino Médio, com as problematizações de conceitos e práticas; investigação da realidade educacional com elaboração de projetos de investigação e/ou ação no espaço escolar e em outras realidades educacionais (UEPG, 2006). Para a formação do gestor e do coordenador pedagógico, é imprescindível o espaço/ tempo que o estágio possibilita para aproximação real do trabalho desses profissionais.

O estágio caracteriza-se como um componente de constituição e desenvolvimento do ser profissional. É nesse espaço que o futuro profissional do ensino entra em contato com o espaço da escola. Para tanto, é necessária uma postura diferenciada daquela que se realiza como aluno ou fiscalizador - é preciso problematizar a escola como parte constituinte de uma totalidade. No entanto, o estágio não se caracteriza como um componente final do curso precisa ser parte de uma sólida formação. No que envolve o PPP (UEPG, 2006) em análise, pontuamos que o estágio em gestão educacional se realiza no último ano do curso e concentram as três etapas do ensino, o que pode dificultar a compreensão das especificidades que envolvem a organização do trabalho pedagógico nesses espaços.

A formação inicial para a pesquisa configura-se como um importante avanço, já contemplado nas DCN (BRASIL, 2006) e que se reafirma no projeto do curso de licenciatura em Pedagogia (UEPG, 2006). Tendo em vista que a formação do professor antes realizada nos Institutos de Educação dispensava a qualificação científica e a apropriação de metodologias para a produção de conhecimento. Nesse sentido, preponderava uma concepção elitista da universidade voltada à formação do pesquisador e do cientista, não cabendo ao magistério o estatuto epistemológico de ciência (KUENZER, 2006). Ao não reconhecer o estatuto epistemológico da formação docente, descaracteriza-se a definição de um saber profissional e específico do professor.

\section{4 | OS CAMINHOS DA PESQUISA}

A formação inicial de Pedagogia da Universidade Estadual de Ponta Grossa/PR constitui-se como o campo de pesquisa deste trabalho. Ao considerar os contextos de atuação do coordenador pedagógico e a influência desses espaços no trabalho dos profissionais, delimitamos nesta pesquisa os coordenadores pedagógicos, egressos no período de 2010 e que atuam nas escolas públicas municipais de Ponta Grossa, a fim de retratar de forma mais precisa a realidade desse contexto.

Após contato com os setenta seis (76) pedagogos, encontramos seis (6) egressos do curso de licenciatura em Pedagogia da UEPG (2007 a 2010), que se encontram na coordenação pedagógica das escolas públicas municipais de Ponta Grossa. Enfatizamos que, do total de seis (6) coordenadoras pedagógicas, três (3) estão atuando no Centros Municipais de Educação Infantil (CMEI), e outras três (3) encontram-se no espaço do Ensino Fundamental nos anos iniciais. Para caracterizarmos as coordenadoras pedagógicas denominamos nesta pesquisa como CP1, CP2, CP3, CP4, CP5 e CP6

A fim de realizar a análise documental do PPP do curso, apoiamo-nos em Lüdke e André (1986) que pontuam sobre a contribuição desse instrumento, que possibilita tanto a exploração de aspectos novos de uma dada pesquisa como também a complementação de outras técnicas de investigação. Lüdke e André (1986) afirmam que a etapa final da análise documental ocorre quando a exploração dessa fonte se torna redundante ou há um acréscimo insignificante de informações.

Ainda, para a coleta dos dados, o outro instrumento utilizado foi a entrevista semiestruturada com os seis (6) sujeitos selecionados, egressos (2007-2010) do curso de licenciatura em Pedagogia da UEPG/PR. De acordo com Triviños (1987), a entrevista semiestruturada compreende como um 
meio fundamental para realizar a investigação, valorizando a liberdade e a espontaneidade do entrevistado e enriquecendo a investigação.

Para compreender os saberes que emergem na formação inicial, utilizamo-nos da análise de conteúdo de Bardin (1977), que a autora caracteriza como um "[...] um conjunto de técnicas de análise das comunicações" (BARDIN, 1977, p. 33). No entanto, não se trata de um instrumento simples, mas de uma análise rigorosa, marcada por diferentes formas e adaptável a um campo vasto de aplicação, nesse caso as comunicações.

Os objetivos elencados por Bardin (1977) para realizar Análise de Conteúdo caracterizam-se na ultrapassagem da incerteza e no enriquecimento da leitura. Para tanto, faz-se necessária uma leitura atenta, pautada pela rigorosidade e a necessidade de descobrir, de ampliar a compreensão sobre determinado objeto. Assim, a análise de conteúdo é uma técnica de investigação que, por meio de uma descrição objetiva e sistemática, tem por finalidade a interpretação dessas mesmas comunicações (BARDIN, 1977).

Diante disso, a última etapa desta pesquisa está pautada na relação entre a análise do PPP (UEPG, 2007) e os dados coletados por meio de entrevista semiestruturada com os egressos do curso em análise. Os procedimentos de análises caracterizam-se por uma classificação de unidades e de significados, criando categorias "[...] introduzindo uma ordem suplementar reveladora de uma estrutura interna" (BARDIN, 1977, p. 55). Diante disso, as entrevistas foram analisadas rigorosamente e agrupadas de acordo com uma estrutura interna, em categorias de análise e de subcategorias. Destacamos neste trabalho a categoria: Formação inicial do coordenador pedagógico com a subcategoria saberes do coordenador pedagógico.

\section{5| SABERES DO COORDENADOR PEDAGÓGICO}

A universidade, espaço de produção e de legitimação dos saberes, precisa compreender aspectos centrais do trabalho dos profissionais que pretende formar. Cabe pontuar que se a concepção do coordenador pedagógico, já no processo formativo, encontra-se fragmentada ou dispersa, isso terá consequência no desenvolvimento de seu trabalho na escola. Nesse sentido, a fala a seguir pontua sobre a dificuldade em reconhecer o trabalho do coordenador pedagógico na formação inicial:

No curso, eu não conseguia perceber o trabalho do coordenador pedagógico, eu não me reconhecia neste trabalho [...]. Inclusive nos primeiros meses como coordenadora eu me via voltando para a sala de aula. (CP4).

O reconhecimento do saber específico do futuro profissional manifesta-se no processo de formação inicial. Gauthier (1998) pondera que a definição de profissão exige, dentre outras características, uma competência como produto de uma formação específica. Com isso, o pertencimento a um grupo profissional requer a apropriação de um conhecimento sistematizado, que se realiza na formação do profissional nos espaços universitários. Desse modo, o trabalho que o coordenador pedagógico exerce na escola está atrelado à formação inicial. No relato a seguir, a coordenadora pedagógica pontua sobre a importância do curso de Pedagogia no trabalho que realiza na escola:

Eu nunca tinha trabalhado em escola e foi lá que eu aprendi tudo. Não me acho diferente de uma pessoa que teve Magistério, eu não tive Magistério. Tudo que eu aprendi foi na Pedagogia como organização pedagógica, metodologia, planejamento. A base para o trabalho que realizo hoje, eu tive no curso. Quando eu cheguei na Prefeitura, eu não tive alguém para me orientar, eu não sabia nem preencher um livro de chamada, ninguém me ensinou e eu não tinha experiência em escola, eu aprendi lá no curso de Pedagogia, nos estágios e nas disciplinas. (CP2). 
No que tange os saberes teórico-práticos do coordenador pedagógico, Gimeno Sacristán (1999, p. 33) corrobora que a ação de um agente é dotada "[...] de sentido, de significados e de valor; algo que se empreende por alguma razão e que tem um fim". Nesse sentido, as ações pedagógicas ultrapassam a perspectiva de aplicação de técnicas ou de teorias sobre educação. $O$ coordenador pedagógico mobiliza saberes no cotidiano escolar, identificando seu trabalho como intencional, organizado, planejado e sistemático. André e Vieira (2007) acentuam que o saber que fundamenta o trabalho do coordenador pedagógico se disponibiliza quando o profissional pensa, planeja, organiza, redimensiona, as próprias ações.

O relato a seguir pontua sobre a teoria que se faz presente nas atividades realizadas pelo coordenador pedagógico:

Porque tem muito da teoria que você vai precisar. E você vê, plenamente, a pessoa que tem um certo descaso com algumas questões, às vezes é por não conhecer. Então, é necessário, por exemplo, para o preenchimento de uma ata, saber o que é direito da criança, o que você vai cobrar, porque é uma questão familiar. Tem situações que você vai encaminhar para outros órgãos, mas não é você que vai tentar resolver, sabe? E você vê que a pessoa não domina a área. Daí você já tem que ficar mais atento. Porque numa equipe é o trabalho de todos que precisa ser estabelecido, e daí você precisa resolver esse tipo de situação se for necessário. (CP4).

Assim, os saberes constituídos no processo de profissionalização do coordenador pedagógico estão embasados por uma epistemologia da ciência que fundamenta seu trabalho. Gauthier (1998) denomina, como o saber das ciências da educação, um conjunto de saberes adquiridos no processo de formação do professor, que nem sempre está diretamente relacionado às ações do coordenador pedagógico, mas que direciona e fundamenta seu trabalho. A seguir, a coordenadora pedagógica aponta os saberes da ciência como pano de fundo no trabalho do coordenador pedagógico, ao relatar a importância da filosofia para compreender o ser humano:

Teve aula que era muita teoria, mas aula de didática dava para fazer essa junção com a sala de aula, aula de gestão, até a própria aula de Filosofia, não com a escola, mas como lidar com o ser humano. (CP2).

Os saberes que envolvem o coordenador pedagógico são multifacetados e não se limitam aos saberes das ciências, e nem tão pouco aos saberes disciplinares. Há, ainda, os saberes profissionais, éticos, políticos, relacionais, entre outros que se manifestam no cotidiano do trabalho do coordenador pedagógico (ANDRÉ; VIEIRA, 2007). A dicotomia teoria e prática da formação do coordenador pedagógico interfere no modo como os saberes vão se relacionar durante sua atuação, os quais acabam se sobrepondo de acordo com o processo de profissionalização. Assim, os saberes do coordenador pedagógico não são apreendidos no vazio, o coordenador mobiliza saberes de acordo com sua trajetória pessoal e profissional. A coordenadora pedagógica entrevistada coloca a importância da trajetória na escola para a mobilização de saberes na função que exerce:

É fundamental essa experiência para o coordenador, porque ele tem que passar pela sala de aula, por vários segmentos e por várias modalidades, Educação Infantil, EJA, Ensino Fundamental. Porque, senão, você não tem uma prática certa. Às vezes você fala para o professor: "Ah, o autor fala isso! E que se você ensinar daquele jeito, dá certo!". Mas será que dá mesmo? (CP5). 
Como pondera Gimeno Sacristán (1999), a prática pedagógica, entendida como uma práxis, é dotada de sentido. Assim, a atuação do professor em sala de aula é um importante espaço mobilizar saberes, definir estratégias e legitimar práticas pedagógicas para o trabalho do coordenador pedagógico. Com esse entendimento, Gauthier (1998) elege o saber experiencial como um espaço/tempo privilegiado do profissional da educação, o qual busca mecanismos para sua prática pedagógica e a reproduz de acordo com as necessidades. O saber adquirido durante a trajetória das coordenadoras pedagógicas na qualidade de professoras, em atuação em sala de aula, é reconhecido também pela entrevistada como um componente importante para orientar o trabalho dos professores:

Sem a experiência pedagógica de sala de aula, eu jamais conseguiria orientar as minhas professoras como eu oriento agora. Porque não adianta querer orientar uma coisa que você não sabe fazer. (CP6).

Ao compreender o coordenador pedagógico como parte integrante da equipe docente, defendemos que sua atuação possui como fim o processo de ensino e aprendizagem dos alunos. Assim, os saberes da experiência tornam-se um mecanismo para o coordenador pedagógico compreender o trabalho docente e intervir quando necessário. No entanto, segundo Ferreira (2011), os saberes não se esgotam no saber fazer e no saber o que ensinar, é preciso ressaltar o saber articulador e o trabalho orgânico para a verdadeira qualidade do trabalho pedagógico. Dessa forma, a experiência em sala de aula não ganha sentido em si mesma, é preciso estar relacionada a outros saberes. Gauthier (1998) elucida que a experiência tem característica privada, ou seja, individualmente o docente reproduz e elabora sua própria jurisprudência. Para o autor, o aspecto privado das experiências, bem como a falta de verificação por meio de métodos científicos, limita o saber na medida em que ele se basta com argumentos e pressupostos. No relato seguinte, a coordenadora pedagógica coloca a importância de compreender a realidade da sala de aula:

Se eu chego, no caso, e assumo uma coordenação sem a vivência em sala de aula, eu não ia saber a realidade como que é. (CP3).

É inegável que o coordenador pedagógico precisa compreender aspectos da docência, tendo em vista que cabe a esse profissional a responsabilidade de subsidiar o trabalho docente. Contudo, para além da esfera da docência, o coordenador pedagógico carece de domínio dos demais procedimentos que envolvem a organização do espaço escolar. Desse modo, a prática em sala de aula não se realiza de forma desligada; pelo contrário, está correlacionada à dinâmica curricular, ao Projeto Político Pedagógico e ao desenvolvimento profissional do professor. Com essa premissa, Domingues (2014) afirma que, para refletir sobre o seu fazer, o coordenador pedagógico precisa estar alicerçado a uma sólida formação em termos conceituais e práticos.

Além de destacar os saberes da experiência para dar suporte à atuação do coordenador peda- gógico, as entrevistadas salientam que o embasamento teórico e prático se torna uma maneira de comprovar os saberes do trabalho desenvolvido:

Agora, é aquela questão que eu te falei de ser testado né, então, as pessoas vão te testar para ver até onde vai o teu conhecimento. (CP4).

Quando você tem a experiência em sala de aula você prova por A+B que dá certo, então é importante você passar por sala de aula. (CP5). 
A experiência docente e o arcabouço teórico tornam-se, assim, critérios para legitimar o trabalho realizado pelo coordenador pedagógico, que passa a ser reconhecido, assim como a trajetória profissional em sala de aula ou dos conhecimentos adquiridos no processo formativo. Gauthier (1998) aborda que o repertório de conhecimentos específicos contribui para definir o status profissional; assim, defendemos que, do mesmo modo que é necessário um repertório de conhecimentos para ensinar, também se torna indispensável um arcabouço de saberes específicos do trabalho do coordenador pedagógico.

Entretanto, Pinto (2011) destaca que não basta ao coordenador pedagógico ter experiência em sala de aula, é preciso obter saberes que envolvem a organização sistêmica da escola, teorias de currículo, políticas públicas na área de educação escolar, avaliação dos processos de ensino e aprendizagem, entre outros saberes que envolvem a atuação do coordenador pedagógico e que ultrapassam os saberes da experiência em sala de aula. Nesse sentido, destacamos nos relatos a seguir o saber co-participativo, democrático que está presente na atuação do coordenador pedagógico:

Eu fazia parte da equipe dos professores quando fui convidada para assumir como coordenadora pedagógica. Foi complicado em relação às amizades com as outras professoras, pois você não é mais apenas colega das professoras, tive que tomar outra postura. Às vezes eu tenho que dar uma orientação, e, em outras, eu tenho que lembrar algumas normas e as professoras podem não gostar. Então, eu tentei encontrar maneiras de conversar com elas, de me relacionar de forma diferente. Buscando sempre resolver os problemas de maneira coletiva. (CP1).

É preciso saber lidar com as pessoas, para conviver no trabalho com os diferentes pensamentos. No que envolve os conflitos por exemplo é preciso ter calma, compreender que as pessoas não são todas iguais, isso foi coisas que eu aprendi no curso de Pedagogia e no cotidiano da escola. (CP2).

O trabalho do coordenador pedagógico não se restringe aos aspectos burocráticos, quando reconhece e realiza funções que envolvem a orientação, a formação continuada e a elaboração do PPP. Essas ações requerem um trabalho coletivo em situações interativas com a comunidade escolar, que, desse modo, se realizam na busca de construir um espaço democrático na escola. Assim, concordamos com Borges (2004) que os saberes ultrapassam as experiências individuais, que, para o autor, envolvem o trabalho co-participativo, de parcerias e experiências adquiridas em diferentes espaços.

Borges (2004) também pontua que as ações empreendidas pelo profissional da educação estão carregadas de histórias e que, nesse sentido, refletem nas ações que se realizam na escola, podendo, assim, obter um caráter democrático ou não. Os saberes são, acima de tudo, sociais e se modificam e se adaptam nas ações do coordenador pedagógico. Tal pensamento converge com Tardif (2002) que compreende que os saberes são construídos, reconstruídos e mobilizados de acordo com as necessidades profissionais do professor e, do mesmo sentido, do coordenador pedagógico.

O saber curricular é colocado como imprescindível para o trabalho que realiza na escola. No entanto, a entrevistada acentua que esse saber foi pouco aprofundado no curso de Pedagogia o que gerou dificuldades em seu trabalho realizado na escola:

Alguns saberes não foram tão trabalhados no curso e eu considero relevante no meu trabalho na escola, como o currículo que poderia ser mais aprofundado. É preciso um currículo diferenciado para a educação infantil, e isso não foi muito aprofundado no curso. E esse conhecimento me fez falta. Às vezes, na graduação, o acadêmico até pensa que é bom quando o professor não dá muito trabalho, mas depois você percebe que alguns conhecimentos fazem muita falta. (CP1). 
Domingues (2014) acentua o coordenador pedagógico como aquele que orienta a organização curricular e o desenvolvimento do currículo. Para tanto, esse profissional precisa obter saberes curriculares para realizar a assistência direta aos professores na elaboração dos planos de ensino, nas práticas de avaliação da aprendizagem, na formação continuada, nas práticas pedagógicas, entre outras atribuições que lhe são pertinentes. Todavia, é preciso considerar que as ações de formação continuada e orientação que o coordenador pedagógico realiza na escola não devem limitar-se aos saberes curriculares, incluindo assim no seu trabalho a realidade da escola e sua cultura organizacional (PINTO, 2011).

Ao realizar suas atribuições, o coordenador pedagógico precisa mobilizar o saber formador, conforme colocado a seguir:

A formação continuada eu faço na hora atividade com a leitura e discussão. Não há tempo disponível, então eu aproveito a hora atividade. Eu divido o planejamento em três momentos: para fazer o planejamento, para preparar o material que vai ser usado nas aulas e para as discussões. (CP1).

$\mathrm{Na}$ escola, é preciso uma formação mediada pela equipe gestora, deveria haver sempre uma formação. Momentos de aprender e refletir sobre a sua prática e do outro, mas não tem tempo. (CP2).

Segundo Nóvoa (1995), a formação continuada possibilita o desenvolvimento pessoal para produzir a vida do professor, o desenvolvimento profissional para produzir a profissão docente e o desenvolvimento organizacional com a finalidade de produzir a escola. Assim, a formação continuada é parte integrante de um amplo processo formativo, que abrange aspectos históricos, culturais e sociais do ser professor. Desse modo, a escola configura-se como lócus de formação do docente.

Cabe ao coordenador pedagógico articular e mobilizar o saber formador a fim de realizar a formação continuada de forma coletiva e colaborativa. Nessa medida, ao realizar a formação continuada, valoriza-se os conhecimentos docentes, contribuindo para a construção do coletivo escolar. Nesse sentido, o coordenador pedagógico assume a função de articulador, problematizador e mediador na organização da formação continuada no espaço escolar, por meio de referenciais teóricos e uma postura baseada na cooperação, na alteridade e no diálogo, a qual permite que o professor assuma o processo de construção da sua profissão, como protagonista.

\section{6| CONSIDERAÇÕES FINAIS}

Analisar a formação inicial do coordenador pedagógico torna-se uma tarefa árdua quando se coloca em vista as contradições presentes no processo formativo e, consequentemente, no trabalho desse profissional. As contradições refletem um distanciamento das contribuições que foram construídas teoricamente sobre o trabalho do coordenador pedagógico, bem como no processo de formação e nas ações que esse profissional assume na escola.

Outro ponto que questionamos nesta pesquisa é o papel da formação inicial na preparação do coordenador para atuar com base nos saberes pedagógicos da escola. Embora se reconheça a formação inicial como um importante espaço de construção dos saberes do coordenador pedagógico, evidenciamos que a indefinição nas atribuições desse profissional se torna mais agravante quando se considera os modelos assumidos no processo formativo. Conforme analisado, o modelo de formação que ora forma o especialista e o professor, ora o pesquisador, o docente e o gestor resultam em uma compreensão histórica de fragmentação, tanto no perfil como no trabalho que assume esse profissional. 
Os saberes experienciais, co-participativos, curriculares e formadores são destacados nas falas das coordenadoras pedagógicas como fundantes para o profissional compreender o espaço da sala de aula e realizar a orientação do trabalho pedagógico do professor. Dessa forma, o estágio na formação inicial, pautado por uma prática comprometida, também se torna um momento chave para a mobilização desses saberes, que permitem ao futuro coordenador pedagógico compreender as especificidades que envolvem o trabalho realizado tanto em sala de aula como na organização do trabalho pedagógico. Cabe considerar que a qualidade do curso de Pedagogia da UEPG é refutada de forma positiva pelas entrevistadas, que valorizam o trabalho dos professores e a sua dedicação com o espaço público.

Vale destacar que as atribuições que o coordenador pedagógico assume no trabalho da escola vão além da organização do trabalho pedagógico - são atribuições de outros profissionais, como do diretor e do secretário. Nesse sentido, torna-se complexo compreender os saberes que envolvem a formação dos egressos do curso, já que, no contexto de atuação, o coordenador pedagógico secundariza ações e saberes específicos do seu trabalho em detrimento de outras funções. Com isso, o perfil profissional do coordenador pedagógico o aproxima de um multitarefeiro, pois é responsabilizado em assumir atribuições de acordo com as necessidades do espaço escolar. Assim, mobilizar saberes e ações apreendidas no decorrer do processo formativo torna-se irrelevantes já que, para exercer uma atuação desordenada e imediatista, basta obter os conhecimentos técnicos e operacionais. 


\section{Referências}

ANDRÉ, M. E. D. A; VIEIRA, M. M. da S. O coordenador pedagógico e a questão dos saberes. In: ALMEIDA, L. R.; PLACCO, V. M. N. de S. (Orgs.). O coordenador pedagógico e questões da contemporaneidade. 2 ed. São Paulo: Loyola, 2007. p. 11-24.

BARDIN, L. Ánálise de conteúdo. Lisboa: Edições 70, 1977.

BORGES, C. M. F. O professor da educação básica e seus saberes profissionais. Araraquara: JM Editora, 2004.

BRASIL. Resolução No 1, de 15 de maio de 2006. Institui Diretrizes Curriculares Nacionais para o Curso de Graduação em Pedagogia, licenciatura. Diário Oficial [da] República Federativa do Brasil, Poder Executivo, Brasília, DF, 16 maio 2006. Seção 1, n. 92, p. 11-12.

CANÁRIO, R. A escola tem futuro? Das promessas às incertezas. Porto Alegre: ArtMed, 2006.

CRUZ, G. B. 70 anos do curso de Pedagogia no Brasil: uma análise a partir da visão de dezessete pedagogos primordiais. Educação \& Sociedade, Campinas, v. 30, n. 109, p. 1187-1205, set./dez. 2009.

DOMINGUES, I. O coordenador pedagógico e a formação continuada do docente na escola. São Paulo: Cortez, 2014.

FERREIRA, N. S. C. (Org.). A gestão da educação na sociedade mundializada: por uma nova cidadania. Rio de Janeiro: DpeA, 2003.

Supervisão educacional: uma reflexão crítica. 15. ed. Petrópolis: Vozes, 2011.

GAUTHIER, C. Por uma teoria da pedagogia. Pesquisas contemporâneas sobre o saber docente. ljuí, RS: Unijuí, 1998.

GIMENO SACRISTÁN, J. Poderes instáveis em educação. Porto Alegre: ArtMed, 1999.
KUENZER, A. Z. As diretrizes curriculares para o curso de Pedagogia: uma expressão da epistemologia da prática. In: ENCONTRO NACIONAL DE DIDÁTICA E PRÁTICA DE ENSINO - ENDIPE, 13., 2006, Pernambuco, Recife. Anais... Recife: Universidade Federal de Pernambuco, 2006. p. 185-212.

LÜDKE, M.; ANDRÉ, M. E. D. A. Pesquisa em educação: abordagens qualitativas. São Paulo: EPU, 1986.

NÓVOA, A. Formação de professores e profissão docente. In: NÓVOA, A. (Coord.). Os professores e a sua formação, Lisboa: Dom Quixote, 1995. p. 13-33.

Formação de professores e trabalho pedagógico. Lisboa: Educa, 2002.

PABIS, N. O trabalho do pedagogo na escola pública do Paraná. 2014. 197 f. Tese (Doutorado em Educação) Universidade Tuiuti, Curitiba, 2014.

PERRENOUD, P. A prática reflexiva no ofício de professor: profissionalização e razão pedagógica. Porto Alegre: Artmed, 2002.

PIMENTA, S. G. O estágio na formação de professores: unidade teoria-prática. São Paulo: Cortez, 1995.

PINTO, U. A. Pedagogia escolar: coordenação pedagógica e gestão educacional. São Paulo: Cortez, 2011.

SCHÖN, D. A. Educando o profissional reflexivo: Um novo design para o ensino e a aprendizagem. Porto Alegre: Artmed, 2000.

TARDIF, M. Saberes docentes e formação profissional. Petrópolis: Vozes, 2002.

TRIVINÕS, A. N. S. Introdução à pesquisa em ciências sociais: a pesquisa qualitativa em educação. São Paulo: Atlas, 1987.

UEPG. Universidade Estadual de Ponta Grossa. Projeto Pedagógico - Curso de Licenciatura em Pedagogia. 2006. (Processo n 04820 - de 10/08/2006 - aprovado em 05/12/2006 pelo Parecer CEPE n. 159/2006 e Resolução CEPE n¹30/2006). Ponta Grossa: UEPG, 2006. 